Journal of Advanced Research in Fluid Mechanics and Thermal Sciences

Journal homepage: www.akademiabaru.com/arfmts.html ISSN: 2289-7879

\title{
Boundary Layer Flow of Dusty Nanofluid over Stretching Sheet with Partial Slip Effects
}

\author{
Nurul Aisyah Johan ${ }^{1, *}$, Syahira Mansur ${ }^{1}$ \\ 1 Faculty of Applied Sciences and Technology, Universiti Tun Hussein Onn Malaysia (Pagoh Campus), 84600 Pagoh, Johor, Malaysia
}

\begin{tabular}{|c|c|}
\hline ARTICLE INFO & ABSTRACT \\
\hline $\begin{array}{l}\text { Article history: } \\
\text { Received } 9 \text { June } 2021 \\
\text { Received in revised form } 13 \text { August } 2021 \\
\text { Accepted } 17 \text { August } 2021 \\
\text { Available online } 20 \text { September } 2021\end{array}$ & $\begin{array}{l}\text { In this work, the effect of dust particles and slips towards boundary layer flow of dusty } \\
\text { nanofluid was investigated over the stretching horizontal sheet. Three types of } \\
\text { nanoparticles; copper }(\mathrm{Cu}) \text {, aluminium oxide }\left(\mathrm{Al}_{2} \mathrm{O}_{3}\right) \text { and titania }\left(\mathrm{TiO}_{2}\right) \text { were studied. } \\
\text { The governing equations of flow and heat transfer were transformed into non-linear } \\
\text { ordinary differential equations by using similarity transformation. Next, these } \\
\text { equations were solved numerically by using the boundary value problem solver, bvp4c } \\
\text { program of Matlab software. The effects of non-governing parameters including } \\
\text { volume fraction of dust particles, volume fraction of nanoparticles, velocity slip } \\
\text { parameter, and thermal slip parameter were computed, analysed, and discussed. } \\
\text { Lastly, a comparison of present study with existing literature was performed and } \\
\text { achieved excellent agreement. It is found that nanoparticles act as good thermal } \\
\text { conductivity. Besides that, } \mathrm{Al}_{2} \mathrm{O}_{3} \text { and } \mathrm{TiO}_{2} \text { show significant effect on velocity of fluid } \\
\text { and dust phase. }\end{array}$ \\
\hline
\end{tabular}

\section{Introduction}

Studies of heat transfer and momentum in nanofluid have garnered much attention from many researchers, especially in the nanotechnology industry. According to Jama et al., [1], the main objective to enhance heat transfer using nanofluid was to reduce the cost and size of heat exchangers with high heat flux. Indirectly, the energy and materials can be conserved. Industrial applications of nanofluid include radiation in automobiles, cooling of electronic devices, biomedical equipment, and solar energy system. Thus, nanofluid is widely applied in engineering and science fields.

Despite the nanofluid topic has been extensively focused by many researchers, only a few studies have been made at the early discovery. In the 21st century, the nanofluid study has been widely explored and deeply studied every year. The presence of metal nanoparticles in base fluid improves the thermal conductivity of the fluid. Bachok et al., [2] found out that the fluid's effective thermal conductivity improved under the presence of the nanoparticles as both Nusselt number and skin friction increased. This is in good agreement with the findings reported by Anuar and Bachok [3]. Abd

\footnotetext{
* Corresponding author.

E-mail address: aisyah.johan95@gmail.com
}

https://doi.org/10.37934/arfmts.87.2.118126 
Rahman et al., [4] studied that copper has the highest heat transfer rate while titania has the lowest as for Blasius problem. However, the Sakiadis problem showed that alumina has the highest transfer rate. Dust particles are known as impurities which can be found in the environment. Manjunatha et al., [5] studied on the fluid flow with dust particles and found out that the thickness of the momentum boundary layer was reduced under the effect of magnetic. Meanwhile, the Prandtl number affected and reduced the thickness of the thermal boundary layer. As a result, the dusty fluid enhanced the heat transfer rate. Furthermore, the addition of dust particles into the nanofluid flow improved the thermal conductivity of matter due to the interaction between fluid and dust particles towards velocity and temperature. Janke's et al., [6] extended the research work by embedded conducting dust particles into the nanofluid flow. Moving surfaces are commonly used in many manufacturing industries. For example, stretching sheets described as plane with the ability to elongate by velocity on plane and external flow. From the findings of Das et al., [7], both momentum and concentration boundary layer became higher and thicker with the stretching parameter. Meanwhile, Jamaludin et al., [8] proved that stretching sheet had better heat transfer rate than the shrinking sheet. The heat flux on the surface and the skin friction along the surface exhibited a significant effect on the stretching parameters towards the flow field. The existence of slip altered the regulation of flow field. It was also found that different outcomes were produced from the appearance of disturbance parameters towards the flow field. The research work by Nandy and Mahapatra [9] indicated that the velocity slip parameter affected the concentration of nanoparticle, the temperature of the flow field, and the velocity of the flow field. Meanwhile, Aman et al., [10] performed the analysis of partial slip towards the stagnation point flow by using the shooting method. The thermal slip parameter caused a reduction in temperature profile and the thickness of the thermal boundary layer became thinner. An article from Khan et al., [11] found that the slip parameter caused the heat to disperse more quickly to surrounding. Hence, the velocity accelerated while temperature fluid reduced as of shrinking sheet.

In this study, the behaviour of dusty nanofluid flow was studied over a stretching sheet with slip effects on the boundary. The effect of volume fraction of dust particles, volume fraction of nanoparticles, velocity slip parameter, and thermal slip parameter were analysed and discussed. The velocity and temperature profile were evaluated and deliberated in detailed. To the best of our knowledge, investigation of such boundary value is yet to be reported in the literature.

\section{Methodology}

\subsection{Flow Analysis}

In this work, a steady-state boundary layer of viscous and incompressible dusty nanofluid flow was assumed. As shown in Figure 1, the horizontal stretching surface located at $y=0$ was driven by the region of $y>0$. The flow was generated by the stretching of the sheet from the application of two equal and opposites forces along the $x$-axis. The fluid flow was assumed to be under ambient fluid velocity and the stretching velocity was in forms of $U_{w}(x)=a x$ with constant $a>0$, which corresponded to the stretching rate. The velocities were varied linearly. The size of the dust particle was assumed uniform. Spherical shaped dust particles were considered. The number density of dust particles, along with the individual volume fraction of dust and nanoparticles, were considered.

The boundary layer equations that governed the present flow are listed as below

$\frac{\partial u}{\partial x}+\frac{\partial v}{\partial y}=0$ 


$$
\begin{aligned}
& \rho_{n f}\left(1-\phi_{d}\right)\left[u \frac{\partial u}{\partial x}+v \frac{\partial u}{\partial y}\right]=\left(1-\phi_{d}\right) \mu_{n f} \frac{\partial^{2} u}{\partial y^{2}}+K N\left(u_{p}-u\right) \\
& u_{p} \frac{\partial u_{p}}{\partial x}+v_{p} \frac{\partial u_{p}}{\partial y}=\frac{K}{m}\left(u-u_{p}\right) \\
& \frac{\partial u_{p}}{\partial x}+\frac{\partial v_{p}}{\partial y}=0
\end{aligned}
$$

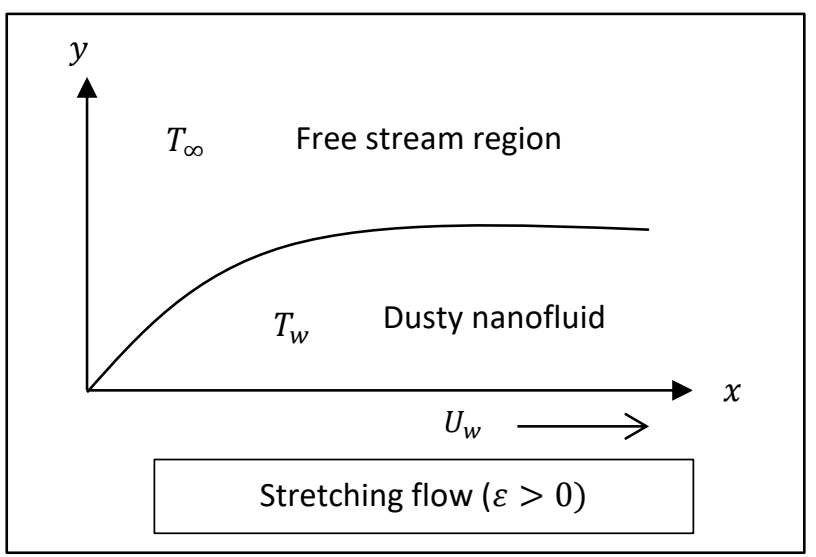

Fig. 1. Physical model and coordinate system

Corresponding to its boundary conditions,

$$
\begin{aligned}
& u=U_{w}(x)+L(\partial u / \partial y), v=0, \text { at } y=0, \\
& u \rightarrow 0, u_{p} \rightarrow 0, v_{p} \rightarrow v \text { as } y \rightarrow \infty
\end{aligned}
$$

where $(u, v)$ and $\left(u_{p}, v_{p}\right)$ are the velocity components of nanofluid and dust phases along the $x$ - and $y$-axes respectively, $\mu_{n f}$ is the viscosity of nanofluid, $\phi_{d}$ is the volume fraction of dust particles, $L$ is the slip length, $K$ is the stokes resistance, $N$ is the number density of dust particles, $m$ is the mass of dust particles, and $\rho_{n f}$ is the density of nanofluid. The nanofluid constants are adapted from Oztop and Abu-Nada [12],

$\rho_{n f}=(1-\phi) \rho_{f}+\phi \rho_{s}$

$\left(\rho c_{p}\right)_{n f}=(1-\phi)\left(\rho c_{p}\right)_{f}+\phi\left(\rho c_{p}\right)_{s}$

$\frac{k_{n f}}{k_{f}}=\frac{\left(k_{s}+2 k_{f}\right)-2 \phi\left(k_{f}-k_{s}\right)}{\left(k_{S}+2 k_{f}\right)+\phi\left(k_{f}-k_{S}\right)}, \mu_{n f}=\frac{\mu_{f}}{(1-\phi)^{2.5}}$

where the subscript $f$ and $s$ refer to fluid and solid properties, respectively. Besides, $\phi$ is the volume fraction of nanoparticles, $\left(\rho c_{p}\right)_{n f}$ is the heat capacity of nanofluid, $\rho_{f}$ and $\rho_{s}$ are the density of the fluid and solid fractions respectively, $k_{n f}$ is the effective thermal conductivity of nanofluid, $k_{f}$ and $k_{s}$ are the thermal conductivities of fluid and solid fractions respectively. According to Abu-Nada [13], the expression $k_{n f}$ is restricted to spherical nanoparticles where it did not account for other shapes of nanoparticles.

The governing Eq. (1) to Eq. (4) were subjected to the boundary condition (5) can be simplified further by introducing similarity transformation, 
$u=c x f^{\prime}(\eta), v=-v_{f}^{\frac{1}{2}} c^{\frac{1}{2}} f(\eta), u_{p}=c x F^{\prime}(\eta), v_{p}=-v_{f}^{\frac{1}{2}} c^{\frac{1}{2}} F(\eta), \eta=v_{f}^{\frac{1}{2}} c^{\frac{1}{2}}$

where $\eta$ is the similarity variable. Eq. (7) identically satisfied Eq. (1) and Eq. (4). Then, Eq. (2) and Eq. (3) becomes

$$
\begin{aligned}
& \frac{1-\phi_{d}}{(1-\phi)^{2.5}} f^{\prime \prime \prime}-\left(1-\phi_{d}\right)\left[1-\phi+\phi\left(\frac{\rho_{s}}{\rho_{f}}\right)\right]\left(f^{\prime 2}-f f^{\prime \prime}\right)+\alpha \beta\left(F^{\prime}-f^{\prime}\right)=0 \\
& F^{\prime 2}-F F^{\prime \prime}-\beta\left(f^{\prime}-F^{\prime}\right)=0
\end{aligned}
$$

Subject to boundary conditions (5),

$f^{\prime}(0)=\varepsilon+\delta f^{\prime \prime}(0), f(0)=0$,

$f^{\prime}(\eta)=0, F^{\prime}(\eta)=0, F(\eta)=f(\eta)$ as $\eta \rightarrow \infty$

From the equations above, the primes denoted differentiation with respect to $\eta$. Meanwhile, $\alpha=$ $\mathrm{Nm} / \rho_{f}$ is the mass concentration of dust particles and $\beta=K / \mathrm{cm}$ is the fluid-particle interaction for the velocity. The velocity ratio parameter is $\varepsilon=a / c$ with $\varepsilon>0$, and $\delta=L\left(\frac{b}{v}\right)^{\frac{1}{2}}$ is the velocity slip parameter.

\subsection{Heat Transfer Analysis}

The boundary layer heat transport of dusty nanofluid flow can be shown as,

$$
\begin{aligned}
& \left(\rho c_{p}\right)_{n f}\left[u \frac{\partial T}{\partial x}+v \frac{\partial T}{\partial y}\right]=k_{n f} \frac{\partial^{2} T}{\partial y^{2}}+\frac{N_{1}\left(c_{p}\right)_{f}}{\tau_{t}}\left(T_{p}-T\right)+\frac{N_{1}}{\tau_{v}}\left(u_{p}-u\right)^{2} \\
& N_{1} c_{m}\left[u_{p} \frac{\partial T_{p}}{\partial x}+v_{p} \frac{\partial T_{p}}{\partial y}\right]=-\frac{N_{1}\left(c_{p}\right)_{f}}{\tau_{t}}\left(T_{p}-T\right)
\end{aligned}
$$

where $T$ and $T_{p}$ are the temperature of nanofluid and dust particles, respectively, $\left(c_{p}\right)_{f}$ and $c_{m}$ are the specific heat of fluid and dust particles, respectively, $N_{1}=N m$ is the density of particle phase, $\tau_{t}$ is the thermal equilibrium time, and $\tau_{v}$ is the dust particle relaxation time.

The temperature boundary conditions are listed below

$$
\begin{aligned}
& T=T_{w}+S\left(\frac{\partial T}{\partial y}\right) \text { at } y=0, \\
& T \rightarrow T_{\infty}, T_{p} \rightarrow T_{\infty} \text { as } y \rightarrow \infty,
\end{aligned}
$$

where $T_{\infty}$ is the ambient temperature, $T_{w}$ is the temperature near the surface meanwhile $S$ is a proportionality constant. To get the similarity solution, below similarity transformation will be applied to transform Eq. (11), Eq. (12) and Eq. (13) 


$$
\begin{gathered}
\theta(\eta)=\frac{T-T_{\infty}}{T_{w}-T_{\infty}}, \theta_{p}(\eta)=\frac{T_{p}-T_{\infty}}{T_{w}-T_{\infty}} \\
T-T_{\infty}=A\left(\frac{x}{\ell}\right)^{2} \theta(\eta), A>0
\end{gathered}
$$

By using Eq. (14), the transformed of ordinary differential equations for Eq. (11), Eq. (12) and Eq. (13) are as below

$$
\begin{aligned}
& \frac{1}{P r}\left(\frac{k_{n f}}{k_{f}}\right)\left(\frac{1}{1-\phi+\phi\left(\frac{\left(\rho C_{p}\right)_{s}}{\left(\rho C_{p}\right)_{f}}\right)}\right) \theta^{\prime \prime}-\left(2 f^{\prime} \theta-f \theta^{\prime}\right)+\left(\frac{1}{1-\phi+\phi\left(\frac{\left(\rho C_{p}\right)_{s}}{\left(\rho C_{p}\right)_{f}}\right)}\right)\left[\alpha \beta_{T}\left(\theta_{p}-\theta\right)+\frac{\alpha E c}{\tau_{v}}\left(F^{\prime}-\right.\right. \\
& \left.\left.f^{\prime}\right)^{2}\right]=0 \\
& 2 F^{\prime} \theta_{p}-F \theta_{p}^{\prime}+\gamma \beta_{T}\left(\theta_{p}-\theta\right)=0
\end{aligned}
$$

along with the transformed boundary condition

$$
\begin{aligned}
\theta(0) & =1+\omega \theta^{\prime}(0) \\
\theta(\eta) & =0, \theta_{p}(\eta)=0 \text { as } \eta \rightarrow \infty
\end{aligned}
$$

where,

$\operatorname{Pr}=\frac{v_{f}\left(\rho c_{p}\right)_{f}}{k_{f}}, \beta_{T}=\frac{1}{c \tau_{T}}, E c=\frac{c l^{2}}{A\left(c_{p}\right)_{f}}, \gamma=\frac{\left(c_{p}\right)_{f}}{c_{m}}, \omega=S\left(\frac{c}{v_{f}}\right)^{\frac{1}{2}}, \ell=v_{f}^{\frac{1}{2}} c^{\frac{1}{2}}$

as $\operatorname{Pr}, \beta_{T}, E c, \gamma, \omega$ and $\ell$ are Prandtl number, fluid-particle interaction parameter for temperature, Eckert number, ratio of specific heat of fluid to dust particles, thermal slip parameter, and characteristic length, respectively.

\section{Results and Discussion}

The nonlinear ordinary differential Eq. (8), Eq. (9), Eq. (15), and Eq. (16) with respect to the boundary conditions (10) and (17) were solved numerically by using the bvp4c program in Matlab software. By using the numerical calculation, these values were kept as constant throughout the entire study except the different values as displayed in respective figures. The values were $\phi=\phi_{d}=$ $0.1, \delta=\beta=\varepsilon=\tau_{v}=0.5, \omega=1.5, \beta_{T}=\alpha=0.2, E c=3$, and $\gamma=2$. The non-dimensional governing parameters were volume fraction of dust particles $\left(\phi_{d}\right)$, volume fraction of nanoparticles $(\phi)$, velocity slip parameter $(\delta)$, and thermal slip parameter $(\omega)$ as presented on both velocity and temperature profiles.

In accordance to Oztop and Abu-Nada [12] and Mahanthesh et al., [14], Prandtl number (Pr) of water was 6.2 and the volume fraction of nanoparticles was found in between 0 and $0.2(0 \leq \phi \leq$ 0.2 ). This study also focused on three types of nanoparticles including copper $(\mathrm{Cu})$, aluminium oxide $\left(\mathrm{Al}_{2} \mathrm{O}_{3}\right)$ and titania $\left(\mathrm{TiO}_{2}\right)$. Table 1 shows the thermo-physical of nanoparticles and base fluid. Several values of Prandtl number in the existing literatures were compared with current results of viscous fluid. From Table 2, one can conclude that the temperature gradient $\left(-\theta^{\prime}(0)\right)$ in this work are relatively similar to that of reported in previous studies. 
Table 1

Thermophysical properties of nanoparticles and base fluid

\begin{tabular}{lllll}
\hline Physical properties & $\begin{array}{l}\text { Density, } \\
\rho\left(\mathrm{Kg} \mathrm{m}^{-3}\right)\end{array}$ & $\begin{array}{l}\text { Specific heat, } \\
c_{p}\left(\mathrm{Kg}^{-1} \mathrm{~K}^{-1}\right)\end{array}$ & $\begin{array}{l}\text { Thermal conductivity, } \\
k\left(\mathrm{Wm}^{-1} \mathrm{~K}^{-1}\right)\end{array}$ \\
\hline Base fluid & $\mathrm{H}_{2} \mathrm{O}$ & 997.1 & 4179 & 0.613 \\
Nano-particles & $\mathrm{Cu}$ & 8933 & 385 & 400 \\
& $\mathrm{TiO}_{2}$ & 4250 & 686.2 & 8.9538 \\
& $\mathrm{Al}_{2} \mathrm{O}_{3}$ & 3970 & 765 & 40 \\
\hline
\end{tabular}

Table 2

Comparison results for the dimensionless temperature gradient $-\theta^{\prime}(0)$ in the case of $\varepsilon=1, \phi=\phi_{d}=$ $\delta=\omega=\beta_{T}=\alpha=\beta=0$

\begin{tabular}{llllll}
\hline $\boldsymbol{P r}$ & Grubka and Bobba [15] & Chen [16] & Abel and Mahesha [17] & Gireesha et al., [18] & $\begin{array}{l}\text { Present } \\
\text { results }\end{array}$ \\
\hline 0.72 & 1.0885 & 1.0885 & 1.0885 & 1.0885 & 1.0886 \\
\hline 1.0 & 1.3333 & 1.3333 & 1.3333 & 1.3333 & 1.3333 \\
\hline 3.0 & 2.5097 & 2.5097 & - & 2.5097 & 2.5097 \\
\hline 10.0 & 4.7969 & 4.7969 & 4.7969 & 4.7969 & 4.7969 \\
\hline
\end{tabular}

Figure 2 and Figure 3 show the effect of volume fraction of nanoparticles $(\phi)$ towards velocity and temperature, respectively. The velocity of fluid increased for both $\mathrm{Al}_{2} \mathrm{O}_{3}$-water nanofluid and $\mathrm{TiO}_{2}$-water nanofluid. On the contrary, the velocity of $\mathrm{Cu}$-water nanofluid reduced as the $\phi$ value increased. Meanwhile, the temperature of all three nanofluids in fluid and dust phase increased. The presence of nanoparticles was found to enhance the heat transfer rate due to its desired size and ability. As the nanoparticles were derived from solid metal, a higher value of density and thermal conductivity were exhibited as compared to the base fluid. Besides density and thermal conductivity, the nano size of particles was found to inhibit clogging, sedimentation, and obstruction phenomena. Thus, a higher volume fraction of nanoparticles in nanofluid improved the heat transfer characteristics.

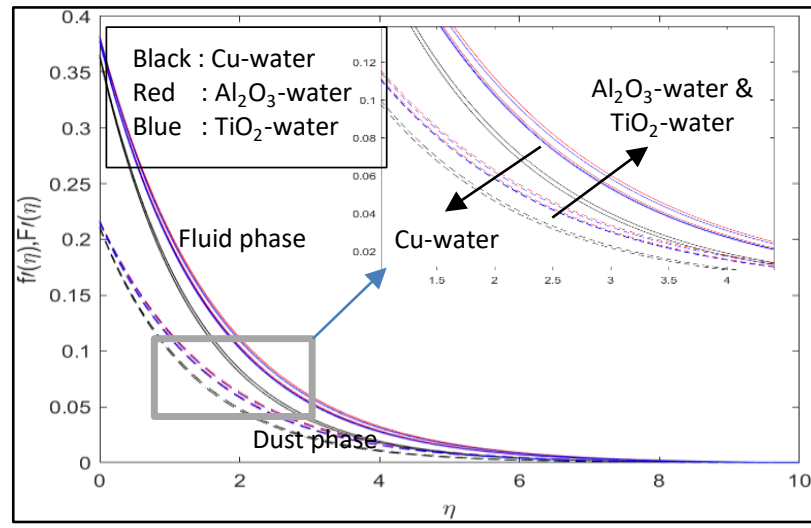

Fig. 2. Velocity profile of fluid and dust phase for different values of $\phi$ (volume fraction of nanoparticles) on 3 types of nanofluid for $\phi=$ $0,0.1,0.2$

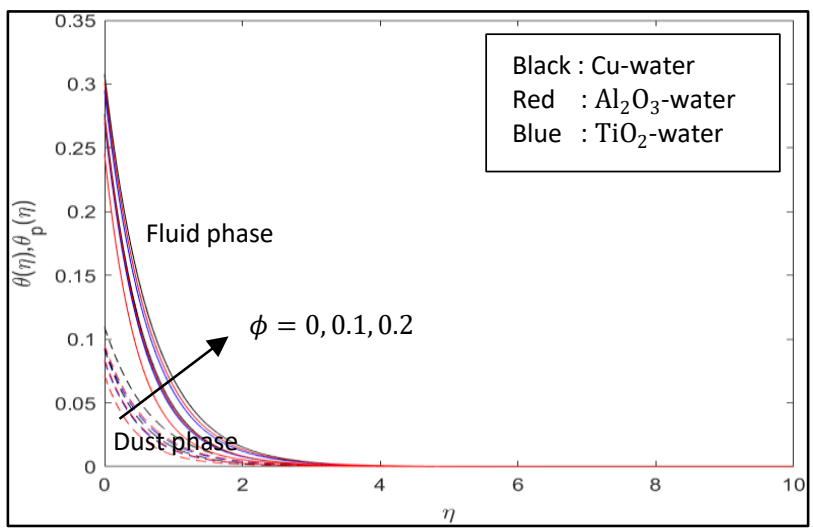

Fig. 3. Temperature profile of fluid and dust phase for different values of $\phi$ (volume fraction of nanoparticles) on 3 types of nanofluid

Figure 4 shows the velocity profile for the volume fraction of dust particles parameter $\left(\phi_{d}\right)$ on dusty nanofluid with $\mathrm{Cu}$-water, $\mathrm{Al}_{2} \mathrm{O}_{3}$-water and $\mathrm{TiO}_{2}$-water. From Figure 4, the velocity was found to be reduced for both fluid and dust phases. This is because the mass concentration of dust particles reduced the pressure inside the boundary layer. Besides that, the presence of dust particles increase 
the shear stress near the wall hence slow down the velocity of fluid. Meanwhile from Figure 5, one can notice that the presence of dust particles could improve thermal conductivity of fluid, evidenced from the increase of $\phi_{d}$.

From the temperature profile, both parameters $\phi$ and $\phi_{d}$ improved the thermal boundary layer. However, there is small increment difference between the parameters can be seen in Figure 3 and Figure 5. This is because the presence of nanoparticles increased the thermal conductivity of fluid due to good interaction with the base fluid. Meanwhile, the dust particles in micro/millimeter size need more interacting mean time as compared to fluid and nanoparticles. This proved that the nanoparticles have better thermal conductivity than dust particles.

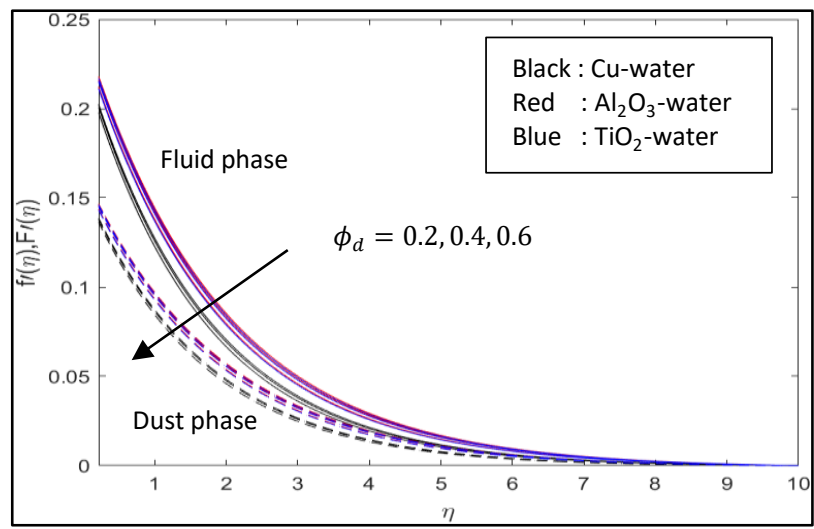

Fig. 4. Velocity profile of fluid and dust phase for different values of $\phi_{d}$ (volume fraction of dust particles) on 3 types of nanofluid

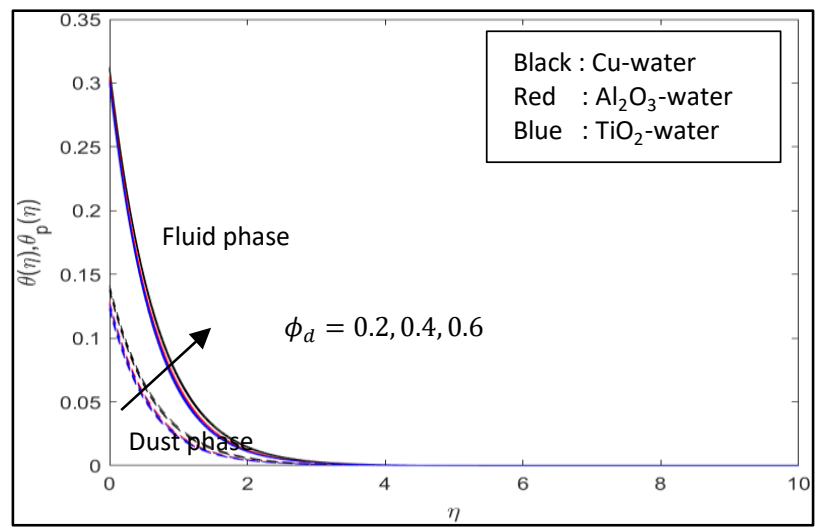

Fig. 5. Temperature profile of fluid and dust phase for different values of $\phi_{d}$ (volume fraction of dust particles) on 3 types of nanofluid

Figure 6 shows the effects of velocity slip parameter $(\delta)$ on the velocity of fluid and dust phases. From Figure 6 , the velocity of both fluid and dust phases was initially in a decreasing trend. As it approached the boundary layer, the velocity of both phases increased. The same trend can be observed in all three nanofluids. Thus, the thickness of the momentum boundary layer became thinner by $\delta$. When the slip occurred, the velocity flow near the sheet was no longer equal to the stretching velocity at the sheet. Hence, the pulling of the stretching sheet partly transmitted to the fluid and caused the fluid velocity declined [9].

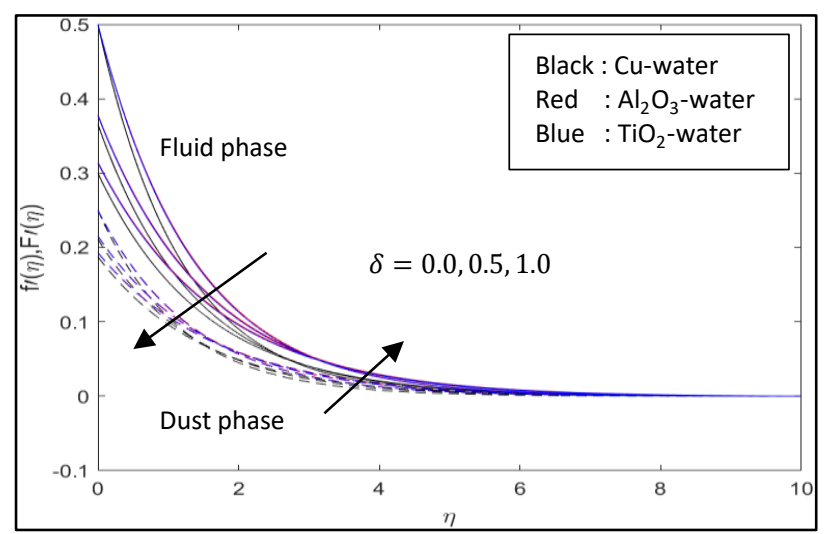

Fig. 6. Velocity profile of fluid and dust phase for different values of $\delta$ (velocity slip) on 3 types of nanofluid 
From Figure 7, the $\delta$ parameter was found to be increased the temperature as the thickness of the thermal boundary layer became thicker. Hence, one can conclude that the $\delta$ parameter improved the heat transfer rate. Figure 8 displays the temperature of the fluid by the parameter of thermal slip $(\omega)$ and it showed a reduction in the thermal conductivity.

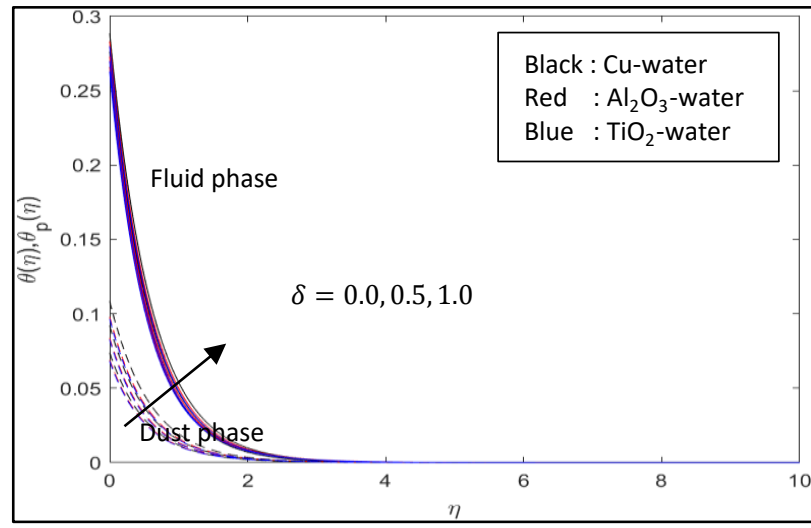

Fig. 7. Temperature profile of fluid and dust phase for different values of $\delta$ (velocity slip) on 3 types of nanofluid

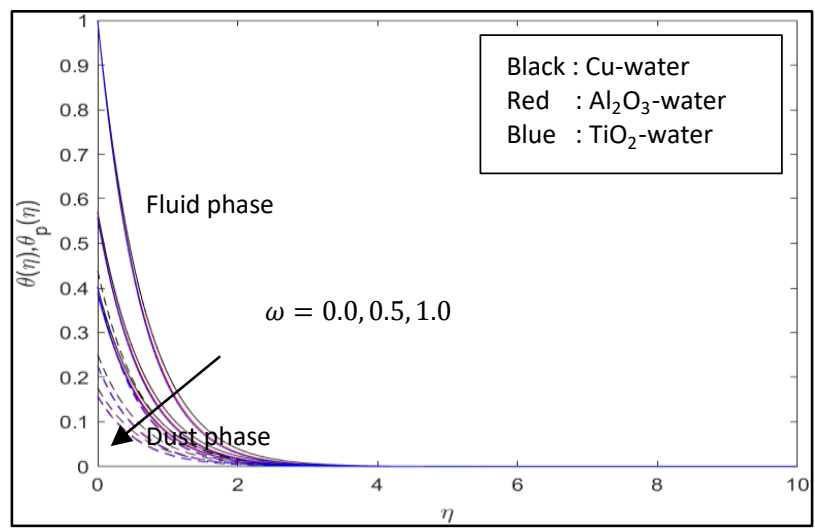

Fig. 8. Temperature profile of fluid and dust phase for different values of $\omega$ (thermal slip) on 3 types of nanofluid

\section{Conclusions}

The current study investigated the boundary layer flow of dust and three type of nanoparticles, namely copper $(\mathrm{Cu})$, aluminium oxide $\left(\mathrm{Al}_{2} \mathrm{O}_{3}\right)$ and titania $\left(\mathrm{TiO}_{2}\right)$. Besides, the velocity slip and thermal slip effects towards the flow were studied as well. To analyse the momentum and heat transfer characteristics, the parameters have been discussed through velocity and temperature profiles.

The present study concluded as follow

i. Nanoparticles have better thermal conductivity than dust particles.

ii. Both $\phi_{d}$ and $\delta$ parameter have positive effects on the momentum boundary layer.

iii. $\phi$ and $\delta$ increased the thickness of the thermal boundary layer, but $\phi_{d}$ and $\omega$ reduced the thickness of the thermal boundary layer.

iv. The velocity of fluid had significant effect towards both $\mathrm{Al}_{2} \mathrm{O}_{3}$ and $\mathrm{TiO}_{2}$ by $\phi$.

\section{Acknowledgement}

The authors are grateful to Research Management Centre (RMC) of Universiti Tun Hussein Onn Malaysia (Project Code: FRGS K056) for the financial support.

\section{References}

[1] Jama, Mohamoud, Tejvir Singh, Seifelislam Mahmoud Gamaleldin, Muammer Koc, Ayman Samara, Rima J. Isaifan, and Muataz A. Atieh. "Critical review on nanofluids: preparation, characterization, and applications." Journal of Nanomaterials 2016 (2016). https://doi.org/10.1155/2016/6717624

[2] Bachok, Norfifah, Anuar Ishak, and Ioan Pop. "Stagnation-point flow over a stretching/shrinking sheet in a nanofluid." Nanoscale Research Letters 6, no. 1 (2011): 1-10. https://doi.org/10.1186/1556-276X-6-623

[3] Anuar, Nur Syazana, and Norfifah Bachok. "Blasius and Sakiadis problems in nano-fluids using Buongiorno model and thermo-physical properties of nano-liquids." European International Journal of Science and Technology 5, no. 4 (2016): 65-81.

[4] Abd Rahman, Nor Hathirah, Norfifah Bachok, and Haliza Rosali. "Boundary-Layer Flow and Heat Transfer of Blasius and Sakiadis Problems in Nanofluids with Partial Slip and Thermal Convection." CFD Letters 11, no. 12 (2019): $53-$ 65 . 
[5] Manjunatha, S., B. J. Gireesha, and C. S. Bagewadi. "Effect of thermal radiation on boundary layer flow and heat transfer of dusty fluid over an unsteady stretching sheet." International Journal of Engineering, Science and Technology 4, no. 4 (2012): 36-48. https://doi.org/10.4314/ijest.v4i4.5

[6] Janke, V. Ramana Reddy, Sandeep Naramgari, and Sugunamma Vangala. "MHD flow of a nanofluid embedded with dust particles due to cone with volume fraction of dust and nano particles." Procedia Engineering 127 (2015): 10261033. https://doi.org/10.1016/i.proeng.2015.11.452

[7] Das, M., B. K. Mahatha, and R. Nandkeolyar. "Mixed convection and nonlinear radiation in the stagnation point nanofluid flow towards a stretching sheet with homogenous-heterogeneous reactions effects." Procedia Engineering 127 (2015): 1018-1025. https://doi.org/10.1016/i.proeng.2015.11.451

[8] Jamaludin, Anuar, Roslinda Nazar, and loan Pop. "Mixed convection stagnation-point flow of a nanofluid past a permeable stretching/shrinking sheet in the presence of thermal radiation and heat source/sink." Energies 12 , no. 5 (2019): 788. https://doi.org/10.3390/en12050788

[9] Nandy, Samir Kumar, and Tapas Ray Mahapatra. "Effects of slip and heat generation/absorption on MHD stagnation flow of nanofluid past a stretching/shrinking surface with convective boundary conditions." International Journal of Heat and Mass Transfer 64 (2013): 1091-1100. https://doi.org/10.1016/i.ijheatmasstransfer.2013.05.040

[10] Aman, Fazlina, Anuar Ishak, and Ioan Pop. "Magnetohydrodynamic stagnation-point flow towards a stretching/shrinking sheet with slip effects." International Communications in Heat and Mass Transfer 47 (2013): 68-72. https://doi.org/10.1016/j.icheatmasstransfer.2013.06.005

[11] Khan, Ansab Azam, Khairy Zaimi, and Teh Yuan Ying. "Stagnation Point Flow of Williamson Nanofluid towards a Permeable Stretching/Shrinking Sheet with a Partial Slip." CFD Letters 12, no. 6 (2020): 39-56. https://doi.org/10.37934/cfdl.12.6.3956

[12] Oztop, Hakan F., and Eiyad Abu-Nada. "Numerical study of natural convection in partially heated rectangular enclosures filled with nanofluids." International Journal of Heat and Fluid Flow 29, no. 5 (2008): 1326-1336. https://doi.org/10.1016/i.ijheatfluidflow.2008.04.009

[13] Abu-Nada, Eiyad. "Application of nanofluids for heat transfer enhancement of separated flows encountered in a backward facing step." International Journal of Heat and Fluid Flow 29, no. 1 (2008): $242-249$. https://doi.org/10.1016/i.ijheatfluidflow.2007.07.001

[14] Mahanthesh, B., B. J. Gireesha, and Rama Subba Reddy Gorla. "Nonlinear radiative heat transfer in MHD threedimensional flow of water based nanofluid over a non-linearly stretching sheet with convective boundary condition." Journal of the Nigerian Mathematical Society 35, no. 1 (2016): $178-198$. https://doi.org/10.1016/j.jnnms.2016.02.003

[15] Grubka, L. J., and K. M. Bobba. "Heat transfer characteristics of a continuous, stretching surface with variable temperature." Journal of Heat Transfer 107 (1985): 248-250. https://doi.org/10.1115/1.3247387

[16] Chen, C-H. "Laminar mixed convection adjacent to vertical, continuously stretching sheets." Heat and Mass Transfer 33, no. 5 (1998): 471-476. https://doi.org/10.1007/s002310050217

[17] Abel, M. Subhas, and N. Mahesha. "Heat transfer in MHD viscoelastic fluid flow over a stretching sheet with variable thermal conductivity, non-uniform heat source and radiation." Applied Mathematical Modelling 32, no. 10 (2008): 1965-1983. https://doi.org/10.1016/j.apm.2007.06.038

[18] Gireesha, B. J., Ali J. Chamkha, N. G. Rudraswamy, and M. R. Krishnamurthy. "MHD flow and heat transfer of a nanofluid embedded with dust particles over a stretching sheet." Journal of Nanofluids 4, no. 1 (2015): 66-72. https://doi.org/10.1166/jon.2015.1126 